\title{
ОРГАНИЗАЦИЯ ДИСТАНЦИОННОГО ОБУЧЕНИЯ ИНОСТРАННОМУ ЯЗЫКУ В ВЫСШЕЙ ШКОЛЕ: ИСПОЛЬЗОВАНИЕ ПЛАТФОРМ COURSERA, ROSETTA STONE, LINGUALEO, MY ENGLISH LAB И SKYENG
}

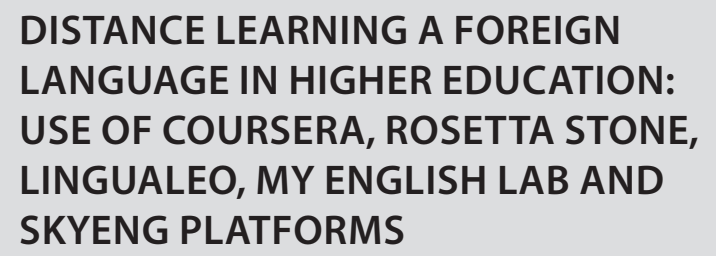

Yu. Valkova

Summary: The article deals with the experience of using Coursera, Rosetta Stone, LinguaLeo, My English Lab and SkyEng platforms for organizing self-study of English in non-specialized higher education institutions under transition to distance learning. The author draws conclusions about the advantages and disadvantages of every platform, provides practical advice on what resources to use depending on the students' level of motivation, self-determination and fluency in English.

Keywords: foreign language teaching, distance education, Coursera, Rosetta Stone, LinguaLeo, My English Lab, SkyEng.

\author{
Валькова Юлия Евгеньевна \\ К.филол.н., старший преподаватель, Финансовый \\ университет при Правительстве РФ (Москва) \\ julyvalkova@gmail.com
}

Аннотация: В статье рассматривается опыт применения платформ Coursera, Rosetta Stone, LinguaLeo, My English Lab и SkyEng для организации самостоятельной работы студентов по английскому языку в неязыковом вузе в условиях перехода на дистанционное образование. Делается вывод о преимуществах и недостатках платформ, даются практические рекомендации, какие ресурсы использовать в зависимости от уровня мотивации, самоорганизации и владения английским языком.

Ключевые слова: преподавание иностранного языка, дистанционное образование, Coursera, Rosetta Stone, LinguaLeo, My English Lab, SkyEng.

ние на таких международных платформах, как Coursera, Rosetta Stone, My English Lab, имеет достоинства в том, что «оно стирает пространственные барьеры, позволяет изучать язык вместе с его носителями из разных стран» [10:190].

Список ресурсов, которые помогают улучшить качества освоения как языкового материал, так и предметных знаний, может составить не одну страницу. Студенты в течение нескольких лет составляли список интересующих их ресурсов, пример можно посмотреть здесь: https://is.gd/JXWMSF Необходимо отметить, что должно быть постоянное обновление списка, так как все время появляются новые Instagram-аккаунты, Telegram-каналы, а некоторые уходят в небытие, поэтому вместо составления списков мы перешли к рекомендациям тех или иных ресурсов, которые именно сейчас актуальны. Такой список включает в себе всего несколько позиций, соответствующих уровню и потребностям группы и может быть легко оценен обучающимися. Неплохим решением для реализации коммуникативной и интенсивной методик, а также метода «погружения» (scaffolding) были бы образовательные инструменты дополненной реальности без привязки к местности [1:49], но они отсутствуют в открытом доступе. 
В условиях дистанционного обучения (во время эпидемии коронавируса в 2020 г.) происходит переориентация на интерактивные онлайн-платформы для повышения эффективности образовательного процесса. Не все студенты имеют техническую возможность посещать организованные для них вебинары, кроме того, по разным причинам сложно достичь того же темпа отработки материала, что был задан при аудиторной работе.

Студенты Финансового университета при Правительстве РФ получили возможность получить бесплатный сертификат по одному из курсов на платформе Coursera. Обычно студенты могут проходить курс бесплатно, только сертификат платный, но в условиях эпидемии, один-два сертификата студенты, указавшие свою принадлежность к университету, могли получить бесплатно. В основном студенты с высоким уровнем владения языком предпочли осваивать курсы, связанные с финансами, в то время как студенты со средним уровнем языка были склонны к выбору курсов на отработку навыков произношения (Tricky American English Pronunciation), грамматики (Adjectives and Adjective Clauses, Perfect Tenses and Modals, Grammar and Punctuation), или обучения языку специальности (English for Business and Entrepreneurship). Студенты с низким уровнем языка не записывались на курсы, так как у них изначально была низкая мотивация. Из плюсов использования этой платформы студенты отметили возможность peer review (когда задания по произношению оценивались теми, кто обучается на курсе в это же время). Студенты услышали произношение других обучающихся, что побудило их к рефлексии над своими ошибками, кроме того, заставило увериться в собственных силах, так как часто работы, которые они сами проверяли, были хуже по качеству, чем их собственные. Кроме того, такая работа по модели «перевернутого класса» поспособствовала их более тщательной подготовки и других своих домашних заданий, не связанных с использованием электронных ресурсов. Из минусов использования Coursera студенты назвали длинные видео-лекции в некоторых курсах, излишнее повторение одного и того же материала (English for Business and Entrepreneurship), недостаточное объяснение методики расчетов (курсы по финансам).

Kроме Coursera студентам предлагались и другие MOOK, но из-за того, что именно Coursera предоставила возможность получения бесплатного сертификата то фокус был смещен в сторону этой платформы. Но по причине того, что у студентов 2 курса есть в программе написание аннотации к статье, они проходили модуль 7 курса «Академическое письмо на русском и английском языках» НИЯУ МИФИ на российской платформе «Открытое образование» и предоставляли преподавателю для зачета скриншот пройденного модуля. В этом модуле обучающиеся узнали, что такое аннотация научного текста, какова ее структура, знакомились со строением пред- ложений аннотации, «словами-помощниками», которые связывают разные структурные части аннотации, с отличиями русскоязычной и англоязычной аннотаций.

Доступ к платформе Rosetta Stone предоставляется на все время обучения в вузе, поэтому многие студенты отложили знакомство с этой платформой, так как к некоторым ресурсам (My English Lab, SkyEng) был предоставлен бесплатный доступ только на время карантина. При первом заходе в систему студенты проходят тестирование на определение уровня языка, благодаря чему задания предоставляются персонализировано (тем не менее, обучающийся волен выбрать задания и другого уровня). Наиболее востребованными у студентов заданиями оказались модули на обучение языку специальности по таким темам, как продажи, переговоры, разговоры по телефону, а также материалы по разным странам, кроме того, есть и модули по банковскому делу, например, то есть здесь речь идет уже не об обучении языку специальности, но об обучении предметным знаниям. Из преимуществ платформы можно перечислить хорошую отработку и наращивание словарного запаса, тренировку всех 4 аспектов владения языком. Коммуникативный подход, изучение грамматики в контексте бытовых ситуаций, симуляция диалогов внутри программы «дает студентам возможность изучать язык в его практическом употреблении без дополнительных усилий на поиск или создание среды общения» [9: 87]. Из недостатков нужно признать необходимость проделать множество однотипных упражнений для закрытия модуля, а также технические перебои системы, когда речь студентов, их микрофоны не распознавались. При этом они не могли завершить освоение данной темы. В дополнение к этому, платформой неудобно пользоваться с мобильных устройств, а в силу того, что студентам удобнее пользоваться именно смартфоном, то другие платформы с возможностью использовать мобильные приложения оказались в выигрыше.

Следующий ресурс - LinguaLeo - был предложен самими студентами, в то время как преподаватель делал упор на более академические платформы. Но в силу того, что ресурс полюбился слабым студентам, было решено оставить его в списке платформ, обучаясь на которых студенты могли получать баллы за самостоятельную работу. Студенты в основном сами выбирали, какие задания им делать, например, осваивали топ-100 наиболее употребительных глаголов, существительных, прилагательных английского языка, читали адаптированные книги на английском, например, Конан Дойля. Из положительных сторон можно указать удобство мобильного приложения, геймификацию процесса (аватар обучающегося - львенок, нужно получать баллы, также есть такие виды упражнений, как саванна или джунгли), коллекцию видео-, аудио-материалов и книг с переводом, титрами и т.Д., причем за собственный перевод можно 
получить баллы. Также из преимуществ использования данной платформы можно упомянуть составление личного словаря с транскрипцией и переводом, тематического словаря с иллюстрацией, разнообразные подходы к тренировкам [4: 72]. Эти преимущества наблюдаются и на платформе Memrise, где можно проходить отработку лексического материала, выращивая «сады памяти», но в описываемый период работа на Memrise не велась из-за широкого использования других инструментов. Из отрицательных сторон Lingua Leo возможно указать ограниченность бесплатного контента. Справедливости ради нужно признать, что в бесплатном доступе есть достаточно ресурсов, в том числе и по языку специальности, у студентов был востребован курс по неправильным глаголам. Тем, кто читал тексты, было предложено не переводить все предложения, так как что чтение аутентичных текстов воспринимается учащимися как своего рода тест, что может превратить чтение в механический перевод каждого слова с помощью личного словаря [13: 65]. Студентам, чьи знания английского языка были близки к нулевым, было рекомендовано приложение DuoLingo, которое интуитивно понятно и тренирует азы языка вплоть до темы условных предложений. Там можно задавать темп занятий в день (5, 10 минут и т.д.), в случае неисполнения плана теряется прогресс обучающегося и приходится снова выполнять одни и те же задания, чтобы пойти дальше, что стимулирует выполнять ежедневный план.

Следующая платформа, к которой студентам был предоставлен бесплатный доступ на 60 дней, это My English Lab (Pearson), как уже неоднократно отмечалось, «лаборатория экономит время преподавателя и студента благодаря возможности моментальной компьютерной проверки домашних заданий и составления «рейтинга» успеваемости учащихся» [7], хотя задания на письмо проверяются учителем. Методика «смешанного обучения» с помощью виртуальной лаборатории My English Lab применяется успешно в МГУ, НИУ ВШЭ и РЭУ им. Плеханова [см. например, 8, 11] для студентов экономических специальностей, но в этих университетах используются пособия издательства Pearson, что облегчает автоматизацию рутинных процессов (назначения и проверки домашнего задания), в то время как в Финансовом университете в аудитории (и на вебинаре) студенты занимаются по пособиям, выпущенным Финансовым университетом, соответственно здесь речь идет не столько о смешанном, сколько о комбинированном изучении.

K My English Lab было подключено пять групп студентов, каждой группе был предоставлен доступ к грамматическому курсу (уровень Intermediate или Advanced) и к курсу, соответствующему учебникам Business Partner Standard / Speak Out Intermediate / Speak Out Advanced / Market Leader Upper-Intermediate / Market Leader Advanced. Студенты либо обсуждали в группе, какой им хотелось бы изучать курс из списка всех доступных курсов, либо преподаватель предлагал несколько на выбор, но финальное решение оставалось за студентами. Кроме указанных уровней, студентам по умолчанию предоставлялся доступ ко всем уровням указанных учебников, соответственно, если было недостаточно знаний по какойлибо теме на уровень Intermediate, то студенты могли делать задания на уровне ниже заданного, но в данном случае преподаватель не видел прогресса и студентам приходилось делать скриншоты диагностики потраченного времени и количества пройденных заданий.

Задания на платформе выполнялись студентами с большим интересом, так как там были представлены небольшие задания, теоретический материал даже по грамматике объяснялся в коротких видеосюжетах, специально записанных для учебных целей и методически соответствующих выбранному уровню (в отличие от LinguaLeo и SkyEng, где используются готовые, хотя и аутентичные ресурсы). Благодаря большому количеству заданий появлялась возможность выбора, преподаватель задавал только необходимый минимум времени, который нужно было провести за выполнением упражнений (30-80 минут в неделю в зависимости от курса студентов, их уровня и программы, а также наличия другой домашней работы). Настройка оценок при автоматизированной проверке производилась согласно требованиям университета (86\%100\% - А (отлично), 70\%-85\% - В (хорошо), 50\%-69\% - С (удовлетворительно), кроме того, были отметки D, E, F, соответствующие более низким уровням освоенности упражнения). Были обязательные домашние задания, для которых студентам давалась одна, в некоторых случаях две попытки. Но по варьируемой части домашнего задания ограничений на попытки не вводилось и можно было проходить задание до тех результатов, которые удовлетворяли самого студента.

Наиболее очевидные преимущества данной платформы - наиболее логичная и грамотная структуризация материала, большое количество заданий на все аспекты владения речью. Студентам предлагалось выполнять задания, соответствующие их учебному плану по грамматике (например, на косвенную речь, каузацию, пассивный залог, модальные глаголы и т.д.), а также те, которые им интересны, за счет чего можно было отрабатывать собственные пробелы. Такая дифференциация самостоятельной работы позволяла наладить работу в разноуровневой группе, и все отзывы обучающихся были положительными. Не все студенты прошли обучение на платформе по следующим причинам:

1. техническая причина - несовместимость операционной системы (1 студент);

2. низкая скорость Интернета, не позволяющая заниматься (3 студента); 
3. низкий уровень мотивации обучающихся (10 студентов, это те же студенты, которые не проявляли и другой активности во время вебинаров);

4. студенты проходили обучение на других платформах / участвовали в кейсах на английском языке и были освобождены от необходимости участия (8 студентов).

К последней рассматриваемой платформе SkyEng был предоставлен бесплатный доступ позже всего, поэтому на нее было предложено записаться тем студентам, которые не смогли по разным причинам заниматься на других платформах, но некоторые студенты из тех, что занимались на других ресурсах, тоже присоединились по собственному желанию. Ресурсы, представленные на платформе, состояли из двух категорий - учебный курс и банк упражнений (были представлены еще материалы к учебному курсу, но они не были интерактивными и не использовались). В качестве учебного курса был выбран курс SkyCareer для уровня B1/B2, он включает в себя 4 юнита с темами релевантными для задачи обучений деловому иностранному языку: Business Trips, Online Correspondence, Networking, Presentations. Эти темы междисциплинарны, развивают у студентов «мягкие навыки», дают необходимую словарную базу для проведения переговоров, совещаний, презентаций. Есть задания на развитие навыков аудирования, чтения, письма, но нет заданий на отработку навыков говорения.

B SkyEng в разделе банк упражнений мы пользовались следующими интерактивными ресурсами: кейсом Internship, где пошагово объяснялись все этапы подачи заявления на стажировку, трудоустройства и т.д. В задание встроена ссылка на сайт с международными стажировками для студентов, что актуализирует изучаемое содержание. Особенный интерес у студентов вызвали задания из раздела Vocabulary Trainers:

1. Real English vs Typical Russian, где нужно было отучаться от русизмов и распознавать «ложных друзей переводчика»;

2. Toast or Roast, где нужно было определять являются ли приведенные высказывания комплиментом или саркастическим комментарием. Во всех заданиях этого типа есть подсказки-объяснения на русском разговорном языке (в том числе обращение на «ты» к обучаемому), поэтому освоение ресурса подходит для студентов с низким уровнем английского языка. Такие задания способствуют «межкультурной сензитивности» [6: 191], пониманию различий между культурами общения, усвоению разных стилей общения.

Из новационных инструментов можно отметить также задания на усвоение местоимений, 2 курса по грамматике (один - на отработку глагольных времен), раздел с заданиями по видео и раздел Choose your own business adventure, темы из которых пересекаются с темами из SkyCareer и Internships (networking, presentations, emailing и т.д.), но сами задания на уровень ниже среднего, поэтому с них студенты и начали освоение этих входящих в любой курс по деловому английскому языку тем. Все задания, представленные на платформе SkyEng, не требуют больших временных затрат, что с одной стороны хорошо для тех студентов, которые имеют сложности с самодисциплиной, с другой стороны - фундаментальных знаний с этой платформы студенты не выносят несмотря на положительные результаты в виде культурологических познаний и эффективному наращиванию словарного запаса благодаря эмоциональной вовлеченности в задания, составленные специально для молодежи. Кроме самой платформы можно пользоваться приложением Aword от SkyEng, которое является хорошим вспомогательным материалом для изучения вокабуляра английского языка, так как основывается на интервальном повторении с учетом кривой забывания Эббингауза [7: 64].

Как и в My English Lab и Rosetta Stone, здесь можно задавать домашние задания студентам, в том числе индивидуально, ставить дедлайны, смотреть статистику и прогресс, что облегчает работу преподавателя с по организации самостоятельной деятельности обучающихся. При использовании MOOK, LinguaLeo и других перечисленных выше платформ студент сам определяет для себя образовательную траекторию.

Таким образом, можно составить сводную таблицу по перечисленным выше ресурсам. Все ресурсы подходят для дискретного и нелинейного обучения, когда студенты могут выбирать отдельные темы для изучения, кроме Coursera и других МООК, когда студенты заинтересованы в получении сертификата. Студентам также было предложено сопоставить и оценить ресурсы, в случае если они пользовались несколькими, что привело к живой дискуссии.

Расшифровка типов аудирования:

1. звукоразличительное аудирование, направленное на восприятие и понимание отдельных звуков;

2. аудирование основного содержания, когда нужно понять самую главную информацию, игнорируя детали;

3. аудирование с полным пониманием, в котором важно и основное содержание, и детали;

4. аудирование с выборочным пониманием, направленное на вычленение и осмысление только интересующей информации или той, которая указана в задании [5].

Можно подвести итоги: только комбинация ресур- 
Таблица 1

Ресурсы для дистанционного обучения иностранному языку

\begin{tabular}{|c|c|c|c|c|c|}
\hline & $\begin{array}{l}\text { Coursera и другие } \\
\text { М00К }\end{array}$ & Rosetta Stone & Lingualeo (Duolingo) & My English Lab & SkyEng \\
\hline чтение & + & + & + & + & + \\
\hline письм0 & зависит от курса & небольшой объем & $\begin{array}{c}\text { отдельные слова, } \\
\text { перевод }\end{array}$ & + & $\begin{array}{c}\text { отдельные слова, } \\
\text { перевод }\end{array}$ \\
\hline аудирование & $\begin{array}{c}+ \\
1 \text { (на спец. курсе), } \\
2,3,4 \\
\end{array}$ & $\begin{array}{c}+ \\
1,2,3,4\end{array}$ & $\begin{array}{c}+ \\
1,2,4\end{array}$ & $\begin{array}{c}+ \\
1 \text { (на спец. курсе), } \\
2,3,4 \\
\end{array}$ & $\begin{array}{c}+ \\
2,4\end{array}$ \\
\hline говорение & зависит от курса & + & $\begin{array}{c}\text { в платной версии, } \\
\text { либо произношение } \\
\text { отдельных слов }\end{array}$ & + & - \\
\hline грамматика & зависит от курса & + & + & + & + \\
\hline язык специальности & +, зависит от курса & + & только на LinguaLeo & + & + \\
\hline предметные знания & + & + & - & - & - \\
\hline $\begin{array}{l}\text { подходит для слабых } \\
\text { студентов }\end{array}$ & - & + & + & + & + \\
\hline $\begin{array}{l}\text { подходит для силь- } \\
\text { ных студентов }\end{array}$ & + & + & - & + & $\begin{array}{c}\text { небольшой объем } \\
\text { заданий }\end{array}$ \\
\hline
\end{tabular}

сов позволяет наладить дистанционную работу в разноуровневой группе, по всем ресурсам есть учет времени, затраченного студентом на усвоение материала, во всех ресурсах есть интерактивная составляющая и автоматизированная проверка, что высвобождает ресурсы преподавателя для более творческой работы. В целом, всем платформам были даны положительные отзывы, но не все студенты признали необходимость использования онлайн-ресурсов для работы. Многие считают свое участие в вебинарах достаточным условием для получения необходимого количества баллов несмотря на то, что самостоятельная работа и количество часов на ее выполнение прописано в учебном плане студентов. Но здесь приходится говорить о непонимании учащимися своей роли в качестве активных участников учебного процесса. Есть прямая корреляция: те студенты, которые проявляли свою активность на вебинарах, динамично осваивали и новые платформы. Как ни странно, несмотря на то, что рассматриваемые в статье онлайн-ресурсы существуют достаточно давно, многие студенты узнали о них впервые от преподавателя в рамках изучаемого курса, кроме того, уровень цифровой компетенции поколения $\mathrm{Z}$ несколько переоценен, так как многие студенты испытывали трудности с регистрацией, ориентацией в интерфейсе, определением своих целей; терялись при необходимости выбора одного-двух курсов из нескольких сотен на платформе Coursera. Необходимо развивать междисциплинарные знания обучающихся, устраивать семинары по онлайнресурсам также и молодому поколению, как это делают сейчас в рамках курсов повышения квалификации для преподавателей. О надобности внедрять в образовательные учреждения адаптивные единые платформы с использованием искусственного интеллекта также рассуждают уже давно [6:25].

Вне зависимости от вида используемой платформы преподаватель тратит большое количество времени на ознакомление с возможностями той или иной платформы, на выработку рекомендаций и составление инструкций для студентов, на мониторинг их успеваемости, поэтому нельзя говорить о том, что цифровые технологии сокращают энергозатраты, но они делают образовательный процесс более увлекательным, разнообразным и продуктивным в условиях дистанционного образования. Достигаются цели коммуникативности, интерактивности, визуализации и персонификации образовательной траектории. Все указанные выше платформы содержат элементы геймификации (прохождение уровней, поощрения (например, вербализованные, как в SkyEng, где ученика хвалят на русском языке), соревновательность. Такая геймификация дает внешнюю мотивацию, не ущемляя при этом внутреннюю [14:6].

Сбор статистики по выполнению заданий позволяет выявить существующие пробелы и подобрать упражнения на их ликвидацию, обнаружить, что интересно студентам для применения именно этих популярных заданий в будущем. Направляя учебный процесс, пре- 
подаватель исполняет роль не только педагога, но и фасилитатора, модератора образовательной деятельности. При готовности и достаточной мотивации студентов можно создавать индивидуальные образо- вательные траектории, что способствует лучшей эффективности учебного процесса особенно в условиях невозможности проводить традиционные аудиторные занятия.

\section{ЛИТЕРАТУРА}

1. Авраменко А.П. Дополненная реальность в языковом образовании: этапы развития, тенденции и перспективы. Информационно-коммуникативные технологии в лингвистике // Ученые записки Национального общества прикладной лингвистики. - 2019. - № 2(26). - С. 47-55.

2. Ачкасова Н.Н. 0 важности вопросов управления образовательным процессом на занятиях по английскому языку в вузе // Современная наука: актуальные проблемы теории и практики. Серия: Гуманитарные науки. - 2020. - №01/2. - С. 20-23.

3. Глазырина Н.С., Кинтонова А.Ж., Ермангабетова М.А., Майкибаева Э.К. Технологии адаптивного обучения // Вестник современных исследований. - 2018. - № 11.3 (26). - С. 22-26.

4. Загерсон М.Э. Инновационные методы формирования лексической компетенции // Лингвистика и межкультурная коммуникация: Материалы Всероссийской научно-практической конференции / под ред. Т.В. Воронченко. Забайкальский государственный университет (Чита). - 2018. - С. 71-73.

5. Кизатов Б.Т., Мадибаева С.К. Трудности восприятия иноязычной речи при аудировании // Путь науки. - 2015. - № 5(15). - С. $102-104$.

6. Кондина А.С. Обзор активных методов формирования межкультурной компетенции в процессе обучения иностранному языку // Информация и образование: границы коммуникаций. Горно-Алтайский государственный университет. - 2019. - № 11(19). - С. 190-192.

7. Корнакова В.И. Организация обучения студентов по методу интервального повторения (кривой забывания) // Проблемы лингвообразования в неязыковом вузе: материалы III Республиканской научно-практической конференции (с международным участием) - 2019. - С. 63-66.

8. Марнат 0.Б. Blended learning как современная форма обучения иностранным языкам в ВУЗе // Электронный научный журнал. - 2016. - № 1(4). - С. 215-218.

9. Матюкина Т.В., Федосеева Т.В. Преимущества использования инновационной языковой программы Rosetta Stone@Advantage в учебном процессе неязыкового вуза // Актуальные проблемы гуманитарных и естественных наук. - 2017. - № 3(2). - С. 87-89.

10. Минеева Н.А. Особенности создания онлайн-платформы для изучения иностранного языка дистанционно // Язык, культура, коммуникация. Проблемы теории, практики и дидактики перевода. Вып. 22. - 2019. - С. 186-191.

11. Мишуненкова О.В. Информационно-коммуникационные технологии обучения иностранному языку в профессиональной подготовке кадров для цифровой экономики // Бизнес. Образование. Право. - 2020. - № 1(50). - С. 397-401.

12. Тенева Е.В. Использование современных информационных технологий в процессе обучения английскому языку // Культура и образование. - Декабрь 2013. - № 4 [Электронный ресурc]. URL: http://vestnik-rzi.ru/2013/12/1163 (дата обращения: 18.05.2020).

13. Федосеева А.В, Интерактивный онлайн-курс «Уроки чтения - праздник, который всегда с тобой»: использование онлайн-ресурса при обучении чтению на подготовительном факультете // Русский язык за рубежом. - 2018. - № 6 (271). - С. 63-66.

14. Androsova I.G., Gerasimenko T.L., Lobanova E.I., Nisilevich A.B., Strizhova E.V. Technology support for teaching majors at the University // Статистика и экономика. - 2015. - №6. - C. 3-6. 